\title{
Occurrence and removal of illicit drugs in different wastewater treatment plants with different treatment techniques
}

\author{
Yanghui Deng ${ }^{1,2}$, Changsheng Guo ${ }^{1}$, Heng Zhang ${ }^{1}$, Xingxing Yin ${ }^{1}$, Like Chen ${ }^{1}$, Daishe $\mathrm{Wu}^{2}$ and Jian Xu ${ }^{1 *}$ (1)
}

\begin{abstract}
Background: As a class of contaminants of emerging concern (CECs), illicit drugs should be taken into account in the water management because of their social and public health risks. Wastewater treatment plants (WWTPs) are usually considered as the source and sink of contaminants, and drug residues are observed in their effluents due to the inefficient removal of CECs. In this study, wastewater samples were collected from eight WWTPs in Changzhou City for assessment of the abuse of 12 illicit drugs in the city by wastewater-based epidemiology (WBE) method.

Results: Drug concentrations ranged from $<$ LOD-51.62 ng/L to $<$ LOD-22.44 ng/L in influent and effluent samples, respectively. The highest removal rate of drugs was $79.0 \%$ in the WWTP which used sequencing batch reactor activated sludge (SBR) process method, while the lowest was found in the WWTP using anoxic oxic (A/O) process (47.0\%), indicating that the drug removal rates were closely related to the treatment techniques. WBE method was applied to estimate the population normalized illicit drugs consumption. It demonstrated that methamphetamine (METH) was the most abused drug in Changzhou City, ranging from 0.16 to $20.65 \mathrm{mg} / \mathrm{d} / 1000 \mathrm{inh}$, while other target drugs ranged from < LOD-1.52 mg/d/1000 inh. Consumption of cocaine (COC) and ecstasy was very low among the samples.
\end{abstract}

Conclusion: Overall, this research suggests that drug removal rates varied in different WWTPs and the SBR process is the best for removing illicit drugs. All target drugs were incompletely removed in wastewater treatment plants. WBE can be readily used to monitor the abuse of drugs in those regions, compared with traditional monitoring models.

Keywords: Illicit drugs, Wastewater-based epidemiology, Removal, Methamphetamine

\section{Background}

The consumption of illicit drugs has been a growing concern worldwide. World Drug Report of 2018 points out that more than 275 million residents around the world were taking drugs, with thousands of tons of illicit drugs consumed annually [1]. In China more than 2.4 million residents consumed drugs at least once in 2017 [2]. Ultimately, illicit drugs enter the wastewater system as

\footnotetext{
*Correspondence: xujian@craes.org.cn

1 State Key Laboratory of Environmental Criteria and Risk Assessment, State Environmental Protection Key Laboratory of Ecological Effect and Risk Assessment of Chemicals, Chinese Research Academy of Environmental Sciences, Beijing 100012, China

Full list of author information is available at the end of the article
}

unaltered forms or/and metabolites. These drugs were excreted after human consumption, or they were released illegally after police intervention [3]. Studies on the occurrence of target compounds in raw waters from wastewater treatment plants (WWTPs) supply invaluable information on illicit drug using and consumer trends at local, national and international levels [3-6]. The method called "wastewater-based epidemiology (WBE)" [4, 7-10] could assess the consumption of illicit drugs by local people, which has been confirmed by traditional approaches [11]. Limited researches have been conducted to investigate the occurrence of illicit drugs in the influents and effluents in WWTPs in China $[5,7,8]$.

Illicit drugs may cause potential risk to aquatic organism and human health when they enter the natural water 
environment $[7,8,12]$. The effluents from WWTPs were the principal source of illicit drugs in the surface water [13]. The elimination efficiency of illicit drugs varied compound by compound in WWTPs. For instance, the removal rate of amphetamine (AMP) and cocaine (COC) was more than $90 \%$, while the removal efficiency of 3,4-methylenedioxymethamphetamine (MDMA) or methamphetamine (METH) was below 50\% [14-17]. The majority of illicit drugs cannot be completely removed in the traditional WWTPs, and a great number of illicit drugs were able to get in the surface water, groundwater and drinking water sources with the discharged effluent [18].

In the present study, we reported the detection of 12 illicit drugs in both influents and effluents from eight WWTPs using different treatment techniques in Changzhou city, east China. To our best knowledge, this is the first detailed investigation on the occurrence and removal of illicit drugs in different WWTPs with different treatment techniques. The total consumption amounts of target drugs in the sampling period were estimated using WBE. Furthermore, the removal rates of target analytes in the WWTPs were assessed, and the effect of various wastewater treatment techniques on the drugs removal was determined as well.

\section{Materials and methods}

\section{Reagents and chemicals}

The target illicit drugs, including methamphetamine $(\mathrm{METH})$, cocaine $(\mathrm{COC}), 3,4-$ methylenedioxymethamphetamine (MDMA), benzoylecgonine (BE), amphetamine (AMP), methadone (MET), norketamine (NK), codeine (COD), ketamine (KET), 3,4-methylenedioxyamphetamine (MDA), methcathinone (MC), heroin (HR), and methamphetamine- $\mathrm{d}_{8}\left(\right.$ METH- $\left.\mathrm{d}_{8}\right)$ with purities greater than $98.2 \%$, were purchased from Cerilliant Corporation (Round Rock, TX) (Fig. 1). Formic acid (FA) (99\%) was obtained from Sigma-Aldrich (Steinheim, Germany) and ammonium hydroxide $\left(\mathrm{NH}_{3} \mathrm{H}_{2} \mathrm{O}\right)$ was obtained from J\&K Scientific (Beijing, China).<smiles>CC(N)Cc1ccccc1</smiles>

Amphetamine<smiles>CC(N)Cc1ccc2c(c1)OCO2</smiles><smiles>CNC1(c2ccccc2Cl)CCCCC1=O</smiles>

Ketamine<smiles>COC(=O)C1C(OC(=O)c2ccccc2)CC2CCC1N2C</smiles>

Cocaine<smiles>CNC(C)Cc1ccccc1</smiles>

Methamphetamine<smiles>CNC(C)Cc1ccc2c(c1)OCO2</smiles><smiles>CN1[C]2CC[C]1C(C(=O)O)[C](OC(=O)c1ccccc1)C2</smiles>

Benzoylecgonine<smiles>CCC(=O)C(CC(C)N(C)C)(c1ccccc1)c1ccccc1</smiles>

Methadone<smiles>CNC(C)C(=O)c1ccccc1</smiles>

Methcathinone<smiles>NC1(c2ccccc2Cl)CCCCC1=O</smiles>

Norketamine<smiles>COc1ccc2c3c1O[C@@H]1[C@H](CN2C)[C@@H]3C=C[C@H]1O</smiles>

Codeine

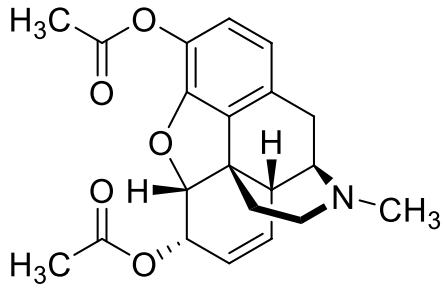

Heroin

Fig. 1 Structure of 12 target illicit drugs and their metabolites in this study 
HPLC-grade methanol $(\mathrm{MeOH})$ and acetonitrile $(\mathrm{ACN})$ were obtained from Fisher Scientific (Poole, UK). Ultrapure water was acquired using a Milli-Q ultrapure water system (Millipore, Bedford, MA, USA).

\section{Sample collection}

Wastewater samples [all samples were collected on the same day and at $60 \mathrm{~min}$ intervals ( $24 \mathrm{~h}$ composites) in a time scale] were taken from $500 \mathrm{~mL}$ of both influents and effluents of 8 WWTPs in Changzhou. The main information of each WWTP is shown in Table 1. All samples were stored in polyethylene terephthalate bottles (adjust all water samples to $\mathrm{pH} 2$, then add $5 \mathrm{ng}$ METH-d8 and EDTA-2Na) and transferred to laboratory in $4{ }^{\circ} \mathrm{C}$ ice box, and treated within $24 \mathrm{~h}$.

\section{Sample preparation and extraction}

The solid-phase extraction (SPE) method was used to extract illicit drugs in the samples according to our previous work [12, 19]. Briefly, wastewater sample was filtered through glass microfiber filters (GF/C Whatman, $0.47 \mu \mathrm{m})$, followed by SPE with Oasis MCX cartridges (60 $\mathrm{mg}, 3 \mathrm{cc}$ ) through a vacuum extraction manifold. With the addition of internal standards, wastewater samples were loaded on the cartridges which were preconditioned with successive $5 \mathrm{~mL}$ of methanol and $5 \mathrm{~mL}$ ultrapure water. After water loading, the MCX cartridge was rinsed by $6 \mathrm{~mL}$ ultrapure water, and drained by a vacuum for half an hour for removing excessive water. The target drugs were eluted from the cartridges by $6 \mathrm{~mL}$ $5 \% \mathrm{NH}_{3} \mathrm{H}_{2} \mathrm{O}$ in $\mathrm{ACN}$. The extract was concentrated with weak $\mathrm{N}_{2}$ stream in the water bath at $40{ }^{\circ} \mathrm{C}$ to dryness, and the volume was brought to $1 \mathrm{~mL}$ with $10 \%$ acetonitrile in water. Prior to the analysis with ultra-performance liquid chromatography equipped with tandem mass spectrometry (UPLC-MS/MS), the extracts were passed through a $0.22 \mu \mathrm{m}$ nylon syringe filter.

\section{Instrumental analysis}

Quantification of analytes was conducted with a Waters triple quadrupole mass spectrometer equipped with an electrospray ionization source under positive electrospray ionization (ESI+) and multiple-reaction monitoring (MRM) mode. The analytes were analyzed within 1 week after sample extraction and were separated with an Acquity UPLC BEH C18 column $(2.1 \mathrm{~mm} \times 50 \mathrm{~mm}$, $1.7 \mu \mathrm{m}$ particle size), and the column temperature was kept at $40{ }^{\circ} \mathrm{C}$ during sample analysis. The Milli- $\mathrm{Q}$ water with $0.1 \%$ FA was used as mobile phase $\mathrm{A}$, and the $\mathrm{ACN}$ as mobile phase $\mathrm{B}$. The velocity of flow was maintained at $0.45 \mathrm{~mL} / \mathrm{min}$, and the volume of injection was $5 \mu \mathrm{L}$. The elution gradient was starting with $98 \%$ of A for $0.5 \mathrm{~min}$, then increased A to $50 \%$ gradually within $4.5 \mathrm{~min}$, and then increased A to $98 \%$ at $4.6 \mathrm{~min}$. The next process was to maintain $\mathrm{A}$ at $98 \%$ for $1.4 \mathrm{~min}$, and then decreased A to $2 \%$ gradually within $6.2 \mathrm{~min}$, and kept constant for $1.3 \mathrm{~min}$ to re-equilibrate before the injection of the next water sample. The total working time was $7.5 \mathrm{~min}$. The ion spray voltage was $4.5 \mathrm{kV}$. The source temperature was $450{ }^{\circ} \mathrm{C}$. The collision gas pressure was 9.0 Psi. Other experimental parameters were listed in Additional file 1: Table S1. The software MassLynx and TargetLynx V4.1 was used to acquire and process the data.

\section{Quantification and quality control}

To determine the accuracy and precision of the analytical approach, Milli-Q water and wastewater samples spiked with deuterated standards were treated with the same pretreatment method. Three types of water (tap water, Milli-Q water and surface water) were spiked with

Table 1 The main information of 8 WWTPs

\begin{tabular}{|c|c|c|c|c|c|c|c|c|}
\hline & TNQ-1 & TNQ-2 & XBQ-1 & XBQ-2 & XBQ-3 & WJQ-1 & JTQ-1 & LYS-1 \\
\hline Treatment process & SBR process & SBR process & $\mathrm{A}^{2} \mathrm{O}$ & $\mathrm{A} / \mathrm{O}$ & $\mathrm{A}^{2} \mathrm{O}$ & $\mathrm{A} / \mathrm{O}$ & $\mathrm{A}^{2} \mathrm{O}$ & $\mathrm{A}^{2} \mathrm{O}$ \\
\hline Average water intake $\left(\mathrm{m}^{3} / \mathrm{d}\right)$ & 15,000 & 25,000 & 160,000 & 3000 & 80,000 & 25,000 & 35,000 & 70,000 \\
\hline People (million) & 0.08 & 0.30 & 0.30 & 0.01 & 0.15 & 0.13 & 0.25 & 0.65 \\
\hline \multicolumn{9}{|l|}{ Influent characteristics } \\
\hline $\mathrm{COD}(\mathrm{mg} / \mathrm{L})$ & 1123 & 780 & 255 & 1185 & 260 & 971 & 265 & 247 \\
\hline $\mathrm{N}(\mathrm{mg} / \mathrm{L})$ & 21.46 & 18.74 & 36.1 & 88 & 31.54 & 12.3 & 35 & 39.62 \\
\hline$P(m g / L)$ & 4.65 & 2.08 & 4.41 & - & 4.46 & 3.02 & 3.42 & 6.95 \\
\hline $\mathrm{NH}_{4}(\mathrm{mg} / \mathrm{L})$ & 21.46 & 18.74 & 23 & 88 & 27.3 & 12.3 & 30 & 28 \\
\hline \multicolumn{9}{|l|}{ Effluent characteristics } \\
\hline $\mathrm{COD}(\mathrm{mg} / \mathrm{L})$ & 178 & 150 & 41 & 51.3 & 32.8 & 60 & 33 & 41 \\
\hline$N(\mathrm{mg} / \mathrm{L})$ & 5.43 & 4.17 & 8.78 & 24.7 & 8.26 & 2 & 10.89 & 8.83 \\
\hline$P(m g / L)$ & 1.69 & 0.95 & 0.15 & - & 0.11 & 0.49 & 0.25 & 0.17 \\
\hline $\mathrm{NH}_{4}(\mathrm{mg} / \mathrm{L})$ & 5.43 & 4.17 & 2 & 24.7 & 2 & 2 & 2 & 2 \\
\hline
\end{tabular}


10 illicit drugs and 2 metabolites at $10 \mathrm{ng} / \mathrm{L}$ to evaluate the recoveries from different matrices. Each sample was analyzed in triplicate to calculate the relative standard deviation (RSD), and non-spiked sample was analyzed to measure the background concentrations simultaneously. The relative recoveries ranged from 73.8 to $92.6 \%$ in tap water, $71.2 \%$ to $85.1 \%$ in Milli-Q water, and $71.8 \%$ to $87.4 \%$ in surface water (Additional file 1: Table S2). For spiking at different concentrations $(0.1,10$, and $50 \mathrm{ng} / \mathrm{L})$ in wastewater, the recoveries ranged from 70.7 to $95.1 \%$. RSDs $<10 \%$ were obtained for each compound (Additional file 1: Table S3). Matrix effect was investigated by spiking the deuterated standards $(5 \mu \mathrm{g} / \mathrm{L})$ into wastewater samples before extraction. A 8-point calibration standard curve $(0.1-10 \mu \mathrm{g} / \mathrm{L})$ was conducted with correlation coefficient $\left(R^{2}\right)$ greater than 0.99 . A procedural blank and a quality control sample $(2 \mu \mathrm{g} / \mathrm{L})$ were injected between every 10 analyses. In the procedural blank the concentrations of target analytes were below the detection limits. The limit of detection (LOD) was calculated by the minimal detectable content (at signal/noise ratio of 3) of a drug from the 12 environmentally matrix-spiked extracts. The LODs for each compound were calculated by MassLynx and TargetLynx V4.1 (Waters, US) from the relative recoveries data of each compound, which were ranging from 0.005 to $0.025 \mathrm{ng} / \mathrm{L}$, with details featured in Table 2 .

\section{Wastewater-based epidemiology}

Wastewater-based epidemiology (WBE) was an effective method to investigate the chemical consumption of the urban population. Combined with traditional survey method, WBE can provide real-time and objective data for drug related policy. WBE assesses daily per capita consumption of drugs by the measured concentration of target residues in population and wastewater, daily flow rate of WWTPs, and human metabolic factors (corrected relationship between target residues and actual drugs) in the service area of WWTPs [7].

The daily mass load of each compound into a certain WWTP was calculated with the equation as follows:

$$
\begin{aligned}
& \text { Influent load of a chemical residue }\left(\frac{\mathrm{mg}}{1000 * \mathrm{~d}}\right) \\
& =\frac{\text { Concentration of a illicit drug }\left(\frac{\mathrm{ng}}{\mathrm{L}}\right) * \text { Influent flow }\left(\frac{\mathrm{L}}{\mathrm{d}}\right)}{\text { Population served } / 1000} * \frac{1}{10^{6}} .
\end{aligned}
$$

The influent concentration of the illicit drug was experimentally determined. Average influent flow on every sampling day was provided by each WWTP. Similarly, WWTPs supplied population from serving community.

\section{Results and discussion}

\section{Illicit drugs in wastewater}

Concentrations of 12 illicit drugs in both influents and effluents from 8 WWTPs are summarized in Table 3. $\mathrm{METH}, \mathrm{COC}$ and KET were the most frequently observed compounds, which were found in all influent samples. The detection frequencies of AMP, MC, COD, $\mathrm{HR}, \mathrm{MET}, \mathrm{MDMA}$, and MDA in influents were greater than $75 \%$, whereas BE was only detected in the WWTP TNQ-2 (Table 3). METH concentrations ranged from 1.28 to $51.62 \mathrm{ng} / \mathrm{L}$ and from <LOD to $22.4 \mathrm{ng} / \mathrm{L}$ in the influents and effluents, respectively. The lowest and highest average concentrations of METH were observed at WJQ-1 (1.20 $\pm 0.5 \mathrm{ng} / \mathrm{L})$ and XBQ-1 (51.62 $\pm 3.5 \mathrm{ng} / \mathrm{L})$, respectively. In general, METH concentrations in the

\begin{tabular}{|c|c|c|c|c|c|c|c|}
\hline Analytes & $R_{t}(\min )$ & Rel. $R_{t}(\min )$ & $\begin{array}{l}\text { Linearity range } \\
(\mu \mathrm{g} / \mathrm{L})\end{array}$ & Calibration curve & $R^{2}$ & $\operatorname{LOD}_{\mathrm{S} / \mathrm{N}}(\mu \mathrm{g} / \mathrm{L})$ & $\mathrm{LOQ}_{\mathrm{S} / \mathrm{N}}(\mu \mathrm{g} / \mathrm{L})$ \\
\hline AMP & 1.86 & 0.08 & $0.1-10$ & $Y=19,828.7 x-554.71$ & 0.9995 & 0.01 & 0.015 \\
\hline METH & 2.04 & 0.08 & $0.1-10$ & $Y=40,079.6 x-265.875$ & 0.9987 & 0.005 & 0.01 \\
\hline$M C$ & 1.67 & 0.08 & $0.1-10$ & $Y=36,872.3 x-1050.63$ & 0.997 & 0.01 & 0.02 \\
\hline MDA & 1.93 & 0.07 & $0.1-10$ & $Y=11,955.7 x-417.15$ & 0.9992 & 0.02 & 0.025 \\
\hline MDMA & 2.04 & 0.08 & $0.1-10$ & $Y=47,352.2 x-1614.27$ & 0.9985 & 0.005 & 0.01 \\
\hline NK & 2.22 & 0.07 & $0.1-10$ & $Y=36,217.3 x-663.94$ & 0.999 & 0.01 & 0.02 \\
\hline KET & 2.29 & 0.07 & $0.1-10$ & $Y=44,710.4 x+3013.45$ & 0.9997 & 0.02 & 0.05 \\
\hline BE & 2.27 & 0.07 & $0.1-10$ & $Y=23,465.0 x-597.23$ & 0.9988 & 0.005 & 0.01 \\
\hline COD & 1.76 & 0.07 & $0.5-10$ & $Y=2682.0 x-131.27$ & 0.9978 & 0.01 & 0.05 \\
\hline $\operatorname{coc}$ & 2.74 & 0.07 & $0.1-10$ & $Y=21,003.5 x-10.74$ & 0.997 & 0.025 & 0.02 \\
\hline MET & 3.99 & 0.08 & $0.1-10$ & $Y=27,369.3 x-4660.57$ & 0.9988 & 0.01 & 0.02 \\
\hline$H R$ & 2.64 & 0.07 & $0.1-10$ & $Y=803.6 x-55.84$ & 0.995 & 0.02 & 0.05 \\
\hline
\end{tabular}
present study were similar to the influent levels from 
Table 3 Concentration and frequency of detection of the target illicit drugs and their metabolites in the influent and effluent (ng/L)

\begin{tabular}{|c|c|c|c|c|c|c|c|c|c|}
\hline Compound & TNQ-1 & TNQ-2 & XBQ-1 & XBQ-2 & XBQ-3 & WJQ-1 & JTQ-1 & LYS-1 & Freq. (\%) \\
\hline \multicolumn{10}{|l|}{ METH } \\
\hline Influent & 5.13 & 1.95 & 51.62 & 1.21 & 35.61 & 1.20 & 6.58 & 45.08 & 100.00 \\
\hline Effluent & 0.38 & 0.47 & 16.59 & $<\mathrm{LOD}$ & 8.24 & 0.74 & 19.71 & 22.44 & 87.50 \\
\hline \multicolumn{10}{|l|}{ AMP } \\
\hline Influent & 8.11 & 1.43 & $<L O D$ & 2.22 & 2.82 & 1.19 & 10.29 & 4.27 & 87.50 \\
\hline Effluent & $<L O D$ & 1.03 & 1.06 & $<\mathrm{LOD}$ & $<\mathrm{LOD}$ & 1.06 & 1.22 & 1.29 & 62.50 \\
\hline \multicolumn{10}{|l|}{ KET } \\
\hline Influent & 1.72 & 0.78 & 0.78 & 0.90 & 2.50 & 1.05 & 0.87 & 0.96 & 100.00 \\
\hline Effluent & $<\mathrm{LOD}$ & 0.19 & 0.86 & 0.35 & 1.21 & 0.70 & 0.94 & 1.01 & 87.50 \\
\hline \multicolumn{10}{|l|}{ NK } \\
\hline Influent & 0.38 & $<\mathrm{LOD}$ & 0.73 & 0.34 & $<L O D$ & 0.23 & 0.16 & $<L O D$ & 62.50 \\
\hline Effluent & 0.58 & 0.27 & 0.36 & 0.31 & $<L O D$ & 0.18 & 0.33 & 0.18 & 87.50 \\
\hline \multicolumn{10}{|l|}{ COD } \\
\hline Influent & 10.71 & $<\mathrm{LOD}$ & $<\mathrm{LOD}$ & 0.80 & 0.81 & 0.40 & 0.42 & 0.94 & 75.00 \\
\hline Effluent & 0.00 & 0.42 & 0.34 & 0.61 & $<\mathrm{LOD}$ & 0.46 & 0.30 & 0.39 & 75.00 \\
\hline \multicolumn{10}{|l|}{$H R$} \\
\hline Influent & 0.00 & 0.38 & 0.30 & 0.74 & 0.37 & 0.46 & 6.99 & $<L O D$ & 75.00 \\
\hline Effluent & 1.53 & 0.34 & 0.42 & 0.69 & 0.34 & 0.43 & 1.81 & 0.40 & 100.00 \\
\hline \multicolumn{10}{|l|}{ MET } \\
\hline Influent & 0.44 & 1.24 & 0.14 & 0.60 & $<\mathrm{LOD}$ & 0.72 & $<L O D$ & 0.09 & 75.00 \\
\hline Effluent & $<L O D$ & 0.09 & $<L O D$ & 0.19 & $<\mathrm{LOD}$ & 0.10 & $<L O D$ & 0.10 & 50.00 \\
\hline \multicolumn{10}{|l|}{$\mathrm{COC}$} \\
\hline Influent & 0.75 & 0.38 & 0.18 & 0.51 & 0.18 & 0.30 & 0.19 & 0.21 & 100.00 \\
\hline Effluent & 0.49 & 0.19 & 0.18 & 0.40 & 0.18 & 0.20 & 0.19 & 0.19 & 0.00 \\
\hline \multicolumn{10}{|l|}{$\mathrm{BE}$} \\
\hline Influent & $<L O D$ & 0.19 & $<\mathrm{LOD}$ & $<\mathrm{LOD}$ & $<L O D$ & $<L O D$ & $<L O D$ & $<L O D$ & 12.50 \\
\hline Effluent & $<L O D$ & $<\mathrm{LOD}$ & $<\mathrm{LOD}$ & $<\mathrm{LOD}$ & $<L O D$ & $<L O D$ & $<L O D$ & $<L O D$ & $<L O D$ \\
\hline \multicolumn{10}{|l|}{ MDMA } \\
\hline Influent & 0.48 & 0.00 & 0.30 & 0.55 & 0.00 & 0.21 & 0.26 & 0.18 & 75.00 \\
\hline Effluent & 0.67 & 0.18 & 0.49 & $<\mathrm{LOD}$ & 0.21 & 0.22 & $<L O D$ & 0.19 & 75.00 \\
\hline \multicolumn{10}{|l|}{ MDA } \\
\hline Influent & 1.75 & 0.24 & 2.74 & $<\mathrm{LOD}$ & $<\mathrm{LOD}$ & 1.10 & 4.85 & 2.18 & 75.00 \\
\hline Effluent & 0.60 & $<L O D$ & 0.24 & $<\mathrm{LOD}$ & 0.46 & 0.25 & 2.36 & 0.39 & 75.00 \\
\hline \multicolumn{10}{|l|}{ MC } \\
\hline Influent & 0.61 & 0.28 & 2.16 & 0.95 & $<L O D$ & 2.69 & 6.58 & 1.62 & 87.50 \\
\hline Effluent & 0.50 & 0.67 & 0.18 & 1.23 & 0.31 & 0.19 & $<L O D$ & 0.58 & 87.50 \\
\hline
\end{tabular}

WWTPs at Nanjing, Shanghai and Nanning cities in China [8], slightly higher than in eastern Canada and Dutch sewage water [20], slightly lower than in UK WWTPs [21], and much lower than in WWTPs in Yinchuan, Xiamen and Shenzhen in China [7].

Amphetamine concentrations were lower than LOD at XBQ-1, and the highest AMP concentration was detected at JTQ-1 $(10.29 \pm 1.2 \mathrm{ng} / \mathrm{L})$. Positive correlations were discovered between METH and AMP concentrations $(r=0.88)$. AMP is the main metabolite of
METH and also the ingredient of selegiline, the medicine for treating Parkinson's disease [9]. Studies have shown that the conversion ratio of METH to AMP after metabolism is between 4 and 7\% [7]. It is logical to draw that when the concentration rate of AMP to METH was between 0.04 and 0.1, AMP was mostly derived from the transformation of METH. The ratio of concentration of AMP to METH was greater than 0.1 at most WWTPs in this study, indicating that the emergence of AMP was more likely to be related to the use 
of prescription drug selegiline. This contrasted sharply with the status in European countries where more AMP relative to METH use was detected [22-24].

Ketamine was observed in eight influent samples, and its concentrations were ranging from 0.78 to $2.50 \mathrm{ng} / \mathrm{L}$, while NK was not detected in the influents (Table 3 and Fig. 2). Although KET was widely present in all WWTPs, the degradation product NK could not be detected. Compared with other cities in China, NK was consistently observed in WWTPs in the southern cities of Shenzhen and Guangzhou, with concentrations higher than in Beijing and Shanghai [10], implying the different consumption patterns of KET in different areas of China.

MDMA was observed in $75 \%$ of the samples. And the concentrations of MDMA ranged from 0.18 to $0.55 \mathrm{ng} / \mathrm{L}$ in influents and $0.18-0.67 \mathrm{ng} / \mathrm{L}$ in effluents. These concentrations were lower than many reported levels in countries and regions with high consumption of MDMA, such as the Taiwan ( $\leq$ LOD-4.82 ng/L) [25], US (70 ng/L) [26], UK (13.9 ng/L) [19] and Spain (180 ng/L) [27]. Compared with those cities, Changzhou is a relatively small area with less entertainment places, and the detected MDMA concentrations were nearly 100 times lower than in European countries. Similar to MDMA, low concentration of MDA was observed for $0.24-4.85 \mathrm{ng} / \mathrm{L}$. The concentration range of COC is $0.18-0.75 \mathrm{ng} / \mathrm{L}$, which is far lower than the influent concentration of UK WWTPs (5.1-208.9 ng/L) [28] and Canada WWTPs (289$823 \mathrm{ng} / \mathrm{L}$ ) [29]. A comparative study was conducted in 9 WWTPs in Beijing, Guangzhou, Shenzhen and Shanghai in China [30], indicating that the illicit drug use pattern in China was different from European countries. In China, the use of METH and KET was the main concern, while the most popular ones in European countries were COC and MDMA.

Methadone was observed in more than $50 \%$ of both influents and effluents wastewater samples. Concentrations of MET in the influent were in the range of $\leq$ LOD$1.24 \mathrm{ng} / \mathrm{L}$ and in the effluent for $\leq$ LOD-0.18 ng/L. In this study, the concentrations of MET were lower than the reported levels in other countries, such as the US (62 ng/L) [9], Croatia (94 ng/L) [12] and Belgium (16 ng/L) [10].

\section{Removal of illicit drugs from WWTPs}

The removal efficiency of target analytes depends strongly on the wastewater treatment techniques. A summary of the removal efficiency of each WWTP is presented in Fig. 3. In this study, the treatment techniques of the eight WWTPs included anaerobic anoxic oxic $\left(\mathrm{A}^{2} / \mathrm{O}\right)$ process, anoxic oxic $(\mathrm{A} / \mathrm{O})$ process and sequencing batch reactor activated sludge (SBR) process. The main advantages of the SBR process were fast sedimentation rate, high reaction rate, and good degradation performance for refractory organics. The SBR was therefore more effective for removing illicit drugs in the treatment process, while the $\mathrm{A}^{2} / \mathrm{O}$ and $\mathrm{A} / \mathrm{O}$ processes were mainly used to remove organic N and P. SBR process was able to effectively remove illicit drugs from water, with the highest removal rate for the total 12 target drugs of $79 \%$, followed by the $\mathrm{A}^{2} / \mathrm{O}$ process (73\%). In the SBR process, illicit drugs were firstly eliminated in the primary sedimentation tank, which was likely related to the treatment conditions such as ambient/water temperature, sewage water composition or biological population [9]. The activity of the biomass in the SBR process accelerated the decomposing of
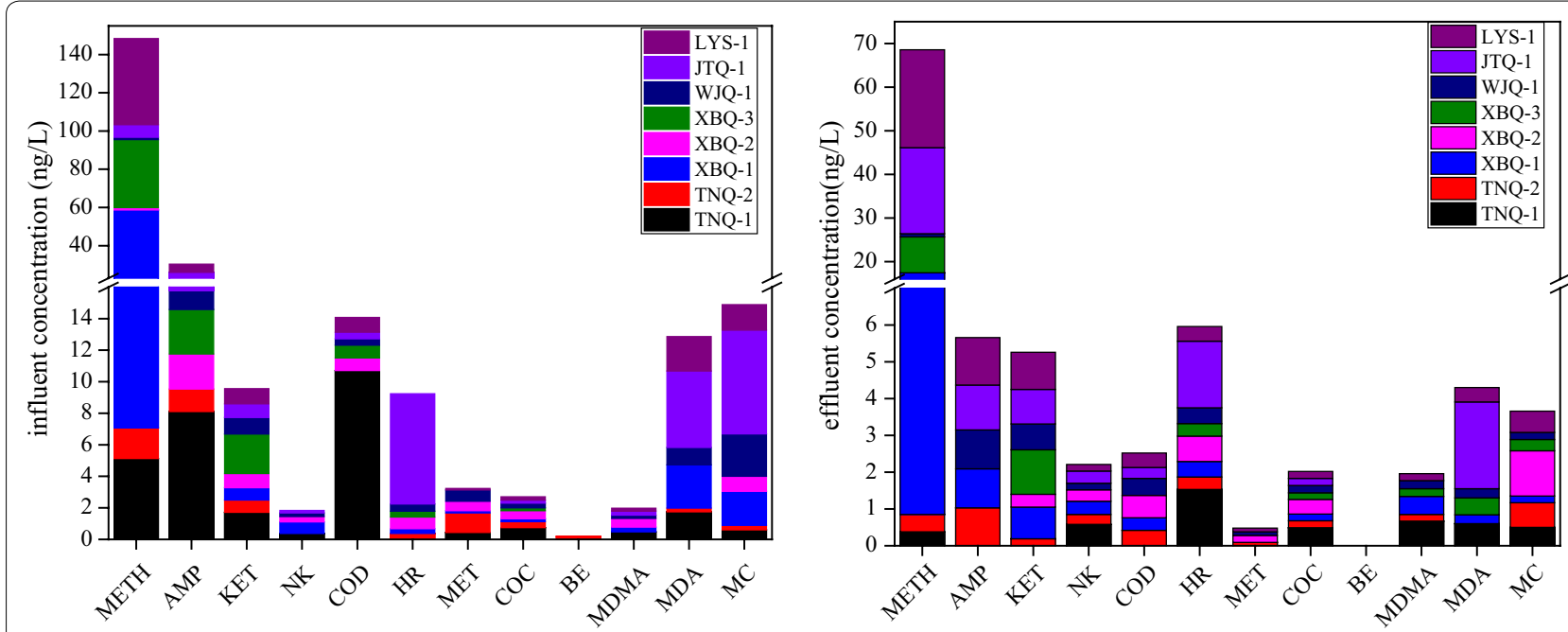

Fig. 2 Average concentrations of target analytes over 24-h period in wastewater influent and effluent of 8 WWTPs 


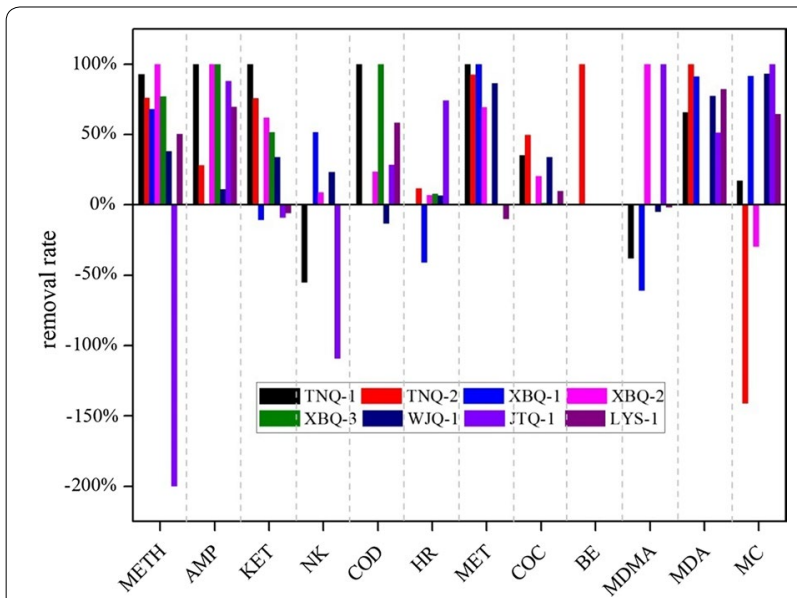

Fig. 3 Comparison of removal efficiency of illicit drugs in the 8 WWTPS

the organic pollutants, resulting in the removal efficiency up to more than $70 \%$.

Most of the investigated illicit drugs and their metabolites are hydrophilic, therefore they are expected to be predominantly present in the dissolved aqueous phase and to adsorb poorly onto solid particles. However, AMP and METH were highly resistant to the biological degradation and they were mainly removed from wastewater by sorption [28, 31-33]. The negative removal of some illicit drugs was also observed in the WWTPs, with the highest negative removal rates of MC and MDMA up to $-155.9 \%$ and $-60.7 \%$, respectively. Negative removal was also reported for KET [20, 24, 28] and other target drugs [9], which may be bound up with the increased transformation of precursor compounds or parent compounds, hydraulic residence time, and/or desorption from suspended solids in the wastewater treatment processes $[23,34]$. Since the influent and effluent samples were not collected on the base of the hydraulic residence time of the WWTPs, the higher concentration found in the effluent for some drugs might be due to the fact that the corresponding influent load was different.

Benzoylecgonine was detected only in the influent of TNQ-2. BE is the major metabolite of COC. COC concentrations were relatively low in all 8 wastewater treatment plants, and the removal rate of $\mathrm{COC}$ in the sewage treatment process was basically below 50\% [27]. This result was inconsistent with the previous study that $\mathrm{COC}$ was easily metabolized into $\mathrm{BE}$, and after human body metabolism, only $1 \%$ will be excreted from urine in the form of $\mathrm{COC}$, and $25-45 \%$ was excreted in the form of $\mathrm{BE}$ $[4,35]$. METH, MET and MDA were effectively removed in different WWTPs, with removal rates ranging from 51.3 to $100 \%$. Conversely, MDMA displayed negative

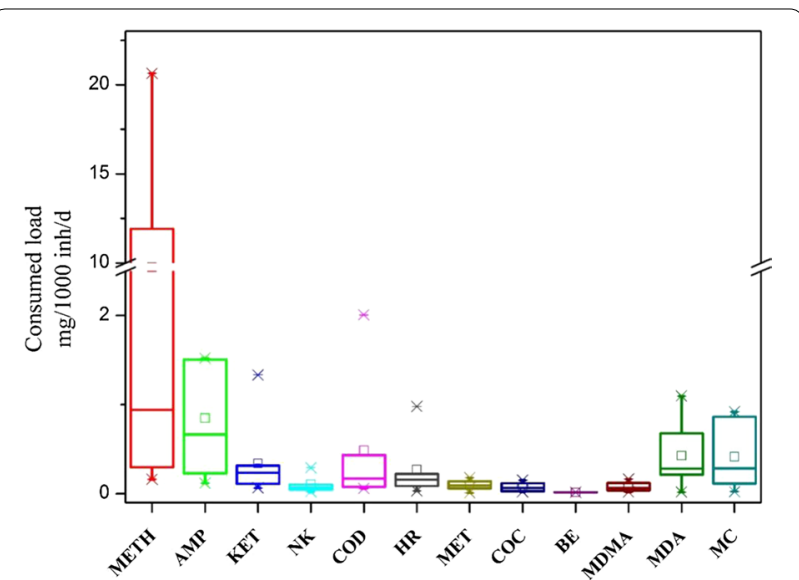

Fig. 4 The estimated illicit drugs consumption per inhabitant in eight wastewater treatment plants in Changzhou City

removal in four WWTPs in this study. The composition and physicochemical properties is shown in Additional file 1: Table S4. This phenomenon was possibly related to its highly recalcitrant property in wastewater and longer half-life of MDMA compared with other target drugs, which may elevate both the persistence of MDMA in wastewater and resistance to biological processes in the secondary treatment procedures [36].

\section{Mean loads of illicit drugs}

Among the 8 WWTPs, LYS-1 receives domestic sewage, XBQ-3 and JTQ-1 receive both domestic sewage and industrial sewage, and the rest 5 WWTPs receive industrial sewage only.

The mass loads of illicit drugs ranged from $0.01 \mathrm{mg} / \mathrm{d} / 1000$ inh (MDMA in LYS-1) to $20.65 \mathrm{mg} / \mathrm{d} / 1000 \mathrm{inh}$ (METH in XBQ-1) (Fig. 4). Average loads of METH, AMP, KET, COD, MDA and MC in the eight WWTPs were $5.89 \pm 8.74,0.84 \pm 0.62,0.34 \pm 0.41$, $0.48 \pm 0.76,0.42 \pm 0.39$ and $0.41 \pm 0.36 \mathrm{mg} / \mathrm{d} / 1000 \mathrm{inh}$, respectively (Table 3 ).

High METH loads were found in XBQ-1 $(20.65 \mathrm{mg} / \mathrm{d} / 1000 \mathrm{inh})$ and XBQ-3 (18.99 mg/d/1000 inh). These loads were lower than those of wastewater samples (1500-1800 mg/d/1000 inh) in Australia [6] and other cities in China such as Haerbin $(181.20 \pm 6.50 \mathrm{mg} / \mathrm{d} / 1000$ inh) [8], Yinchuan $(148.00 \pm 145.20 \mathrm{mg} / \mathrm{d} / 1000 \mathrm{inh})[8$, 12], and the mean METH load in WWTPs from 18 cities in China was $67.80 \pm 45.2 \mathrm{mg} / \mathrm{d} / 1000 \mathrm{inh}$, which was threefold higher than the mean load in this study [8].

COC and MDMA consumption was much lower than METH in this study, ranging from 0.02 to $0.15 \mathrm{mg} / \mathrm{d} / 1000 \mathrm{inh}$ for COC and $0.02-0.16 \mathrm{mg} / \mathrm{d} / 1000$ inh for MDMA. The consumption of COC and MDMA estimated in the present study was lower 
than 20.00-200.00 $\mathrm{mg} / \mathrm{d} / 1000$ inh and 5.00$50.00 \mathrm{mg} / \mathrm{d} / 1000 \mathrm{inh}$, respectively, in WWTPs of South-East Queensland in Australia. The average loading of $\mathrm{MC}$ was $<\mathrm{LOD}-0.92 \mathrm{mg} / \mathrm{d} / 1000 \mathrm{inh}$, which was lower than $0.50 \mathrm{mg} / \mathrm{d} / 1000$ inh in Great Britain and $1.0 \mathrm{mg} / \mathrm{d} / 1000 \mathrm{inh}$ in Italy [35]. The average loading of MET was $0.09 \pm 0.06 \mathrm{mg} / \mathrm{d} / 1000 \mathrm{inh}$, far lower than Sweden $(0.50-29.00 \mathrm{mg} / \mathrm{d} / 1000 \mathrm{inh})$ [37] and Finland (1.2-9.5 mg/d/1000 inh) [24].

The average daily load of MDA and MDMA was $<$ LOD-1.10 and <LOD-0.16 mg/d/1000 inh, respectively. The measured level was comparable with other Chinese cities for Shenzhen and Guangzhou [10], but was much lower than the MDMA load of $5-41 \mathrm{mg} / \mathrm{d} / 1000 \mathrm{inh}$ in the working days of the 25 WWTPs in France [6]. The maximum load of HR was $0.98 \mathrm{mg} / \mathrm{d} / 1000 \mathrm{inh}$, which was much lower than the average HR load of $61 \mathrm{mg} / \mathrm{d} / 1000$ inh in the Ebro River Basin [9]. HR load in Guangzhou and Shenzhen in China was less than $4.0 \mathrm{mg} / \mathrm{d} / 1000$ inh [12], while the HR load in western cities of China was higher. The daily load of COD was <LOD-2.01 mg/d/1000 inh, which was basically consistent with the average COD load of $5.7 \mathrm{mg} / \mathrm{d} / 1000$ inh in South Korean [28], far low than the UK [27], with corresponding load of $565 \mathrm{mg} / \mathrm{d} / 1000$ inh.

Although COD and MET were detected in most WWTPs in this study, the detection concentrations were significantly lower than European cities with the estimated COD load of 2-1998 mg/d/1000 inh [3]. MET and COD are used as controlled medicines in China [38] (In 2018, the State Drug Administration listed COD as the prohibited substance for adolescents and children). In Europe, however, MET is used as an alternative medicine for methadone oral solutions. In most EU countries, COD can be used legally. Drugs containing codeine are approved by national procedures and sold as prescription or over-the-counter drugs in different prescriptions [38].

\section{Conclusions}

In the present study, we investigated the occurrence and elimination of 12 illicit drugs and their metabolites from 8 wastewater treatment plants in Changzhou City. METH, AMP, KET, MDMA and MET were the dominant drugs in these WWTPs, with higher concentrations than other drugs. Among the treatment techniques, SBR process was efficient for removal of illicit drugs, while the removal efficiency of target drugs by $\mathrm{A} / \mathrm{O}$ process was low. Results from wastewater-based epidemiology showed that METH was the most consumed illicit drug, which should draw much attention by regulatory and management communities.

\section{Supplementary information}

Supplementary information accompanies this paper at https://doi. org/10.1186/s12302-020-00304-x.

Additional file 1. Table S1. 12 illicit drugs analyte ions and MS parameters. Table S2. Recoveries (\%) of illicit drugs and their metabolites from different matrix with spiking concentrations of $10 \mathrm{ng} / \mathrm{L}$. Table S3. Recoveries (\%) of 12 illicit drugs and their metabolites in waste water with different spiking concentrations. Table S4. The structural formula, elemental composition and physicochemical properties for 12 illicit drugs and their metabolites. Table S5. Full text abbreviations of professional terms.

\section{Abbreviations}

METH: Methamphetamine; COC: Cocaine; BE: Benzoylecgonine; MDMA: 3,4-Methylenedioxymethamphetamine; AMP: Amphetamine; MET: Methadone; NK: Norketamine; COD: Codeine; KET: Ketamine; MDA: 3,4-Methylenedioxyamphetamine; MC: Methcathinone; HR: Heroin; WWTPs: Wastewater treatment plants; $A^{2} / O$ : Anaerobic anoxic oxic process; A/O: Anoxic oxic process; WBE: Wastewater-based epidemiology.

\section{Acknowledgements}

Not applicable.

\section{Authors' contributions}

$Y D, C G$ and $H Z$ were involved in the experiments and manuscript writing, $X Y$, LC and DW were responsible for the data analysis. JX contributed to the study design and manuscript correction. All authors read and approved the final manuscript.

\section{Funding}

This work was funded by the Chinese National Special Science and Technology Program of Water Pollution Control and Treatment (2017ZX07302001) and National Natural Science Foundation of China (41673120).

\section{Availability of data and materials}

The datasets used and analyzed during the current study are available from the corresponding author on reasonable request.

\section{Ethics approval and consent to participate}

Not applicable.

\section{Consent for publication}

Not applicable.

\section{Competing interests}

The authors declare that they have no competing interests.

\section{Author details}

${ }^{1}$ State Key Laboratory of Environmental Criteria and Risk Assessment, State Environmental Protection Key Laboratory of Ecological Effect and Risk

Assessment of Chemicals, Chinese Research Academy of Environmental Sciences, Beijing 100012, China. ${ }^{2}$ Key Laboratory of Poyang Lake Environment and Resource Utilization, Ministry of Education, School of Resources Environmental and Chemical Engineering, Nanchang University, Nanchang 330031, China.

Received: 16 December 2019 Accepted: 9 February 2020 Published online: 26 February 2020

References

1. UNODC (2018) Global overview of drug demand and supply. http://files erver.idpc.net/library/WDR18_Booklet_1_EXSUM.pdf

2. CNNCC (2018) Report on the drug situation in China. http://www.mps. gov.cn/n6557558/c6535096/content.html

3. ThomasKV BijlsmaL, Castiglioni S, Adrian C, Erik E, Roman G, Félix H, Sara K, Barbara KH, Richard H, Lindberg Miren L A, Axel M, Christoph 
O, Yolanda P, José BQ, Malcolm R, Jörg R, Senka T, van Nuijs ALN, Pim V (2012) Comparing illicit drug use in 19 European cities through sewage analysis. Sci Total Environ 432:432-439

4. Zuccato E, Chiabrando C, Castiglioni S, Renzo B, Roberto F (2008) Estimating community drug abuse by wastewater analysis. Environ Health Perspect 116:1027-1032

5. Gao T, Du P, Xu Z, Li XQ (2017) Occurrence of new psychoactive substances in wastewater of major Chinese cities. Sci Total Environ 575:963-969

6. Nefau T, Karolak S, Castillo L, BoireauV Levi Y (2013) Presence of illicit drugs and metabolites in influents and effluents of 25 sewage water treatment plants and map of drug consumption in France. Sci Total Environ 461-462:712-722

7. Li J, Hou L, Du P, Yang J, Li KY, Xu ZQ, Wang CC, Zhang HF, Li XQ (2014) Estimation of amphetamine and methamphetamine uses in Beijing through sewage-based analysis. Sci Total Environ 490:724-732

8. Du P, Li K, Li J, Xu ZQ, Fu XF, Yang J, Zhang HF, Li XQ (2015) Methamphetamine and ketamine use in major Chinese cities, a nationwide reconnaissance through sewage-based epidemiology. Water Res 84:76-84

9. Postigo C, López de Alda MJ, Barceló D (2010) Drugs of abuse and their metabolites in the Ebro River basin: occurrence in sewage and surface water, sewage treatment plants removal efficiency, and collective drug usage estimation. Environ Int 36(1):75-84

10. Khan U, van Nuijs ALN, Li J, Maho W, Du P, Li KY, Hou LL, Zhang JY, Meng XZ, Li XQ, Covaci A (2014) Application of a sewage-based approach to assess the use of ten illicit drugs in four Chinese megacities. Sci Total Environ $487: 710-721$

11. Reid MJ, Langford KH, Grung M, Gjerde H, Amundsen EJ, Morland J, Thomas KV (2012) Estimationof cocaine consumption in the community: a critical comparison of the results from three complimentary techniques. BMJ Open 2(6):e001637

12. Zhang Y, Zhang T, Guo CS, Lv JP, Hua ZD, Hou S, Zhang Y, Meng W, Xu J (2017) Drugs of abuse and their metabolites in the urban rivers of Beijing, China: occurrence, distribution, and potential environmental risk. Sci Total Environ 579:305-313

13. Chiaia AC, Banta-Green C, Field J (2008) Eliminating solid phase extraction with large-volume injection LC/MS/MS: analysis of illicit and legal drugs and human urine indicators in US wastewaters. Environ Sci Technol 42(23):8841-8848

14. Kasprzyk-Hordern B, Dinsdale RM, Guwy AJ (2008) Multiresidue methods for the analysis of pharmaceuticals, personal care products and illicit drugs in surface water and wastewater by solid-phase extraction and ultra performance liquid chromatography-electrospray tandem mass spectrometry. Anal Bioanal Chem 391(4):1293-1308

15. Boleda MR, Galceran MT, Ventura F (2009) Monitoring of opiates, cannabinoids and their metabolites in wastewater, surface water and finished water in Catalonia, Spain. Water Res 43(4):1126-1136

16. Chiavola A, Tedesco P, Boni MR (2019) Fate of selected drugs in the wastewater treatment plants (WWTPs) for domestic sewage. Environ Sci Pollut Res 26(2):1113-1123

17. Boni MR, Chiavola A, Di Marcantonio C, Sbaffoni S, Biagioli S, Cecchini G, Frugis A (2018) A study through batch tests on the analytical determination and the fate and removal of methamphetamine in the biological treatment of domestic wastewater. Environ Sci Pollut Res 25(28):27756-27767

18. Daughton CG (2001) Illicit drugs in municipal sewage. ACS Symp Ser 791:348-364

19. Guo C, Zhang T, Hou S, Lv JP, Zhang Y, Wu FC, Hua ZD, Meng W, Zhang $\mathrm{H}, \mathrm{Xu} J$ (2017) Investigation and application of a new passive sampling technique for in situ monitoring of illicit drugs in waste waters and rivers. Environ Sci Technol 51(6):9101-9108

20. Metcalfe C, Tindale K, Li H, Rodayan A, Yargeau V (2010) Illicit drugs in Canadian municipal wastewater and estimates of community drug use. Environ Pollut 158(10):3179-3185

21. Baker DR, Kasprzyk-Hordern B (2013) Spatial and temporal occurrence of pharmaceuticals and illicit drugs in the aqueous environment and during wastewater treatment: new developments. Sci Total Environ 454-455:442-456

22. Andrés-Costa MJ, Rubio-López N, Morales Suárez-Varela M, Pico Y (2014) Occurrence and removal of drugs of abuse in wastewater treatment plants of Valencia (Spain). Environ Pollut 194:152-162

23. Östman M, Fick J, Näsström E, Lindberg RH (2014) A snapshot of illicit drug use in Sweden acquired through sewage water analysis. Sci Total Environ 472:862-871

24. González-Mariño I, Gracia-Lor E, Rousis NI, Castrignanò E, Thomas KV, Quintana JB, Kasprzyk-Hordern B, Zuccato E, Castiglioni S (2016) Wastewater-based epidemiology to monitor synthetic cathinones use in different European countries. Environ Sci Technol 50(18):10089-10096

25. Jiang JJ, Lee CL, Fang MD (2014) Emerging organic contaminants in coastal waters: anthropogenic impact, environmental release and ecological risk. Mar Pollut Bull 85(2):391-399

26. Kinyua J, Anderson TA (2012) Temporal analysis of the cocaine metabolite benzoylecgonine in wastewater to estimate community drug use. J Forensic Sci 57(7):1349-1353

27. Baker DR, Očenášková V, Kvicalova M, Kasprzyk-Hordern B (2012) Drugs of abuse in wastewater and suspended particulate matter-further developments in sewage epidemiology. Environ Int 48:28-38

28. Kim KY, Lai FY, Kim HY, Thai PK, Mueller JF, Oh JE (2015) The first application of wastewater-based drug epidemiology in five South Korean cities. Sci Total Environ 524-525:440-446

29. Boleda MR, Huerta-Fontela M, Ventura F, Galceran T (2011) Evaluation of the presence of drugs of abuse in tap waters. Chemosphere 84(11):1601-1607

30. Vazquez-Roigp Andreu V, Blasco C, Picó Y (2010) SPE and LC-MS/MS determination of 14 illicit drugs in surface waters from the Natural Park of L'Albufera (València, Spain). Anal Bioanal Chem 397(7):2851-2864

31. Fernandez-Fontaina E, Omil F, Lema JM, Carballa M (2012) Influence of nitrifying conditions on the biodegradation and sorption of emerging micropollutants. Water Res 46:5434-5444

32. Hörsing M, KosjekT, Andersen HR, Heath E, Ledin A (2012) Fate of citalopram during water treatment with $\mathrm{O}_{3}, \mathrm{ClO}_{2}, \mathrm{UV}$ and Fenton oxidation. Chemosphere 89(2):129-135

33. Álvarez-Ruiz R, Andrés-Costa MJ, Andreu V, Picó Y (2015) Simultaneous determination of traditional and emerging illicit drugs in sediments, sludges and particulate matter. J Chromatogr A 1405:103-115

34. Subedi B, Kannan K (2014) Mass loading and removal of select Illicit drugs in two wastewater treatment plants in New York state and estimation of illicit drug usage in communities through wastewater analysis. Environ Sci Technol 48(12):6661-6670

35. Castiglioni S, Bijlsma L, Covaci A, Emke E, Hernández F, Reid M, Ort CT, Homas KV, van Nuijs ALN, Voogt P, Zuccato E (2013) Evaluation of uncertainties associated with the determination of community drug use through the measurement of sewage drug biomarkers. Environ Sci Technol 47(3):1452-1460

36. Evans SE, Bagnall J, Kasprzyk-Hordern B (2016) Enantioselective degradation of amphetamine-like environmental micropollutants (amphetamine, methamphetamine, MDMA and MDA) in urban water. Environ Pollut 215:154-163

37. Banta-Green CJ, Field JA, Chiaia AC, SudakinDL PowerL, Montigny L (2009) The spatial epidemiology of cocaine, methamphetamine and 3,4-methylenedioxymethamphetamine (MDMA) use: a demonstration using a population measure of community drug load derived from municipal wastewater. Addiction 104:1874-1880

38. INCB (2013) Report of the international narcotics control board for 2013. https://www.unodc.org/documents/lpo-brazil//Topics_drugs/ INCB/2014/AR_2013_E.pdf

\section{Publisher's Note}

Springer Nature remains neutral with regard to jurisdictional claims in published maps and institutional affiliations. 